\title{
KARAKTERISTIK, HAMBATAN-HAMBATAN DAN FAKTOR-FAKTOR YANG MEMPENGARUHI PRODUKSI USAHA KECIL MENENGAH (Studi kasus UKM Batik Tulis Trusmi di Desa Trusmi Wetan dan Kulon Kecamatan Plered Kabupaten Cirebon) \\ Suripto Iman Krismanto ${ }^{2}$ \\ E-mail:suripto@ep.uad.ac.id..
}

Prodi Ekonomi Pembangunan,

Fakultas Ekonomi Dan Bisnis, Universitas Ahmad Dahlan

\begin{abstract}
This study discusses the characteristics, constraints and factors of production of Trusmi written batik SMEs in Trusmi Wetan and Trusmi Kulon Villages, Plered District, Cirebon Regency. The objectives of this study are: (1) analyzing the characteristics of Trusmi handmade batik seen from business owners, the output/products produced and marketing, (2) analyzing the difficulties/obstacles experienced by Trusmi handmade batik UKM, (3) analyzing the influence of factors -factors of production against the amount of batik production Trusmi. This study uses statistical analysis tools both descriptive and inferential. Descriptive analysis is used to determine the characteristics, difficulties and obstacles experienced by SMEs in batik writing. Multiple linear regression is used to determine the effect of variable raw materials, wages, labour, education and business experience on the amount of Trusmi written batik production in Trusmi Wetan and Kulon villages, Plered District, Cirebon Regency. The results showed that (1) the characteristics of owners/entrepreneurs of Batik Tulis Trusmi as many as 15 (50\%) craftsmen started their business background from generation to generation/inheritance and as many as 15 (50\%) the rest were independent business backgrounds. The level of craftsman education is dominated by high school and the average age of the craftsman is 51 years. Products produced by craftsmen in the form of hem/shirt, sarong, shawl and marimbist in their marketing crafters supply several showrooms in Trusmi and are sent to several regions, (2) batik artisans experience difficulties and obstacles in terms of capital, raw materials and human resources, (3) multiple linear regression using individual test (t-test) shows that raw materials and wages have a positive and significant effect on the amount of batik production, while the amount of labour, education and business experience does not affectt.
\end{abstract}

Key word: Small and Medium Enterprises, SMEs, production, characteristics, barrier

\section{PENDAHULUAN}

Perekonomian Indonesia sejak terjadinya krisis moneter tahun 1998 mengalami kesulitan.Keadaanini tidak hanya terjadi pada industri besar atau menengah saja melainkan juga berimbas pada industri kecil.Namun industri kecil inilah yang masih bisa bertahan dibandingkan industri lainnya yang berskala menengah dan besar.Usaha Kecil Menengah (UKM) memiliki kontribusi yang signifikan terhadap pembangunan ekonomi, baik di negara-negara industri maupun negara berkembang. Peran UKM dalam pembangunan ekonomi, antara lain dalam penyerapan tenaga kerja dan peningkatan ekonomi lokal. UKM menyerap tenaga kerja khususnya tenaga kerja informal karena karakteristik pekerjan sektor UKM yang tidak membutuhkan syarat formal seperti halnya perusahaan besar.Sedangkan UKM mampu meningkatkan ekonomi lokal ialah melalui kegiatan perekonomian lokal seperti peningkatan pendapatan masyarakat setempat.

Cirebon merupakan salah satu kabupaten yang ada di Provinsi Jawa Barat.Cirebon memiliki banyak potensi Usaha Kecil Menengah (UKM) yang bisa dikembangkan dengan maksimal.UKM yang berhasil dan sukses karena memiliki kemampuan berfikir 
kreatif dan inovatif. Cirebon mempunyai banyak sekali UKM kreatif dan inovatif yang perlu terus dikembangkan agar mempunyai daya saing terhadap daerah lain. Salah satu UKM yang perlu dikembangkan adalah batik yang merupakan warisan budaya dari nenek moyang sejak zaman dahulu dan telah ditetapkan oleh UNESCO sebagai warisan budaya dunia yang berasal dari Indonesia.

Meski bukan daerah penghasil batik yang terkenal, Cirebon adalah salah satu daerah yang memiliki batik dengan ciri khasnya sendiri. Salah satu batik yang telah lama ada di Kabupaten Cirebon adalah Batik Tulis Trusmi .Trusmi dikenal sebagai salah satu daearah penghasil batik di Cirebon. Sentra UKM batik Cirebon atau lebih dikenal dengan Batik Tulis Trusmi terdapat di Desa Trusmi Wetan dan Trusmi Kulon Kecamatan Plered Kabupaten Cirebon.

Peningkatan nilai tambah di sentra Batik Tulis Trusmi Kabupaten Cirebon masih terkendala masalah klasik yakni kekurangan modal usaha dan pemasaran. Masnedi (2012) mengatakan, masalah permodalan paling berat dirasakan perajin kecil karena perajin tidak mendapatkan pembayaran langsung dari pemesannya.Biasanya pembayaran pesanan baru diterima perajin setelah beberapa minggu pengiriman barang, sehingga selama proses penantian balik modal biasanya produksi mandek Tidak hanya masalah modal usaha dan pemasaran saja yang dihadapi UKM Batik Tulis Trusmi ,Batik Tulis Trusmi masih kalah dengan batik daerah lain seperti batik dari daerah Pekalongan. Saat ini, pasar showroom batik yang ada di Trusmi Kabupaten Cirebon hampir didominasi produk batik dari luar Cirebon seperti Pekalongan.Karena batik Pekalongan kebanyakan diproduksi secara massal, harga jualnya lebih murah dibandingkan batik tulis dan cetak yang diproduksi perajin batik Cirebon http://industri.bisnis.com/read/20120801/87/89178/a kses-modal-ukm-batik-trusmi-cirebon-terhambatmodal).

Menurut Soekesi (2013), perkembangan permintaan pasar yang mampu meningkatkan munculnya sentra batik di berbagai wilayah Indonesia menimbulkan semakin ketatnya persaingan. Jenis batik yang dihasilkan juga berbeda yaitu batik tulis, batik cap, maupun batik kombinasi tulis dan cap. Ditinjau dari aspek pemasaran, setiap jenis batik tersebut mempunyai segmen pasar yang berbeda, sehingga atribut produk batik juga harus disesuaikan dengan segmen pasar masing-masing.Bahkan pesaing tidak hanya dari pasar domestik, tetapi juga dari luar negeri, terutama dari Negara China.Persaingan terebut semakin ketat dengan munculnya tekstil bermotif batik.

\section{TINJAUAN TEORETIS}

Dalam UU RI No 9 Tahun 1995 yang dimaksud usaha kecil adalah kegiatan ekonomi rakyat yang berskala kecil dan memenuhi kriteria kekayaan bersih atau hasil penjualan tahunan serta kepemilikan sebagaimana diatur dalam undang-undang ini.Sedangkan usaha menengah dan usaha besar adalah kegiatan ekonomi yang mempunyai kriteria kekayaan bersih atau hasil penjualan tahunan lebih besar dari pada kekayaan bersih dan hasil penjualan tahunan usaha kecil.

Usaha Kecil Menengah (UKM) menurut UU RI No 20 Tahun 2008 Tentang Usaha Mikro, Kecil, Dan Menengah. Usaha Kecil adalah usaha ekonomi produktif yang berdiri sendiri, yang dilakukan oleh orang perorangan atau badan usaha yang bukan merupakan anak perusahaan atau bukan cabang perusahaan yang dimiliki, dikuasai, atau menjadi bagian baik langsung maupun tidak langsung daru Usaha Menengah atau Usaha Besar yang memenuhi kriteria Usaha Kecil sebagaimana dimaksud dalam Undang-undang ini.

\section{TEORI PRODUKSI}

Menurut Putong (2013:169) yang dimaksud dengan produksi atau memproduksi adalah suatu usaha atau kegiatan untuk menambah kegunaan (nilai tambah) suatu barang. Kegunaan suatu barang akan bertambah bila meberikan manfaat baru atau lebih dari bentuk semula. Untuk memproduksi dibutuhkan faktor-faktor produksi yaitu, alat atau sarana untuk melakukan proses produksi. Menurut Sukirno (2005:193-194) dalam menganalisa bagaimana perusahaan dalam melakukan kegiatan produksi, teori ekonomi membedakan jangka waktu analisis kepada dua jangka waktu yaitu jangka pendek dan jangka panjang.Analisis ke atas kegiatan memproduksi perusahaan dikaitkan di dalam jangka pendek apabila sebagian dari faktor produksi dianggap tetap jumlahnya.Didalam masa tersebut perusahaan tidak dapat menambah jumlah faktor produksi yang dianggap tetap tersebut.Dalam jangka panjang semua faktor produksi dapat mengalami perubahan, ini bebrarti bahwa dalam jangka panjang setiap faktor produksi dapat ditambah jumlahnya kalau memang hal tersebut dibutuhkan.

\section{FUNGSI PRODUKSI}

Fungsi produksi adalah hubugan antara jumlah input yang digunakan dan jumlah output yang dihasilkan. Fungsi produksi menentukan output maksimum yang dapat dihasilkan dari sejumlah tertentu input, dalam kondisi keahlian dan pengetahuan teknis yang tertentu (Samuelson dan Nordhaus, 2003:125). Menurut Sudarsono (1995:121) fungsi produksi adalah hubungan teknis yang menghubungkan antara faktor produksi atau 
disebut pula masukan/input dan hasil produksinya atau produk (output).Menurut Boediono (2011:64) fungsi produksi adalah suatu fungsi atau persamaan yang menunjukan hubugan antara tingkat output dan tingkat/kombinasi penggunaan input-input. Hubungan antara output dan input dari faktor produksi dutunjukan secara matematis sebagai berikut:

$$
\mathrm{Q}=\mathrm{F}(\mathrm{X} 1, \mathrm{X} 2, \mathrm{X} 3 \ldots . \mathrm{Xn})
$$

Fungsi produksi ini menunjukan bahwa $Q$ (Tingkat produksi atauoutput) dipengaruhi oleh input yangdigunakan $(\mathrm{X} 1, \mathrm{X} 2, \mathrm{X} 3, \ldots . . \mathrm{Xn})$. Dalam teori ekonomi diambil pula suatu asumsi dasar mengenai sifat dan fungsi produksi. Yaitu fungsi produksi dari semua produksi di mana semua produsen dianggap tunduk pada suatu hukum yang disebut the law of diminishing return. Hukum ini mengatakan bahwa bila suatu macam input ditambah penggunaannya sedang input-input lain tetap maka tambahan output yang dihasilkan dari setiap tambahan satu unit input yang ditambahkan tadi mula-mula menaik, tetapi kemudian seterusnya menurun bila input tersebut terus ditambah (Boediono, 2011:64).

Di Indonesia, penelitian mengenai peluang dan tantangan UKM salah satunya dilakukan oleh Sutopo (2011) yang berjudul "Produktivitas dan Ketahan Bisnis Industri Kecil". Penelitian industri kecil Batik Tulis Trusmi ini, hanya mencoba melakukan identifikasi, menjelaskan dan mencari apa yang mungkin terjadi dimasa yang akan datang mengingat persaingan pasar domestik maupun pasar global saat ini. Hasil analisis ditemukan adanya penggunaan modal yang tidak efisien, padahal perannya dalam produksi sangat urgen. Peran bahan baku sangat besar dan signifikan, dan ketersediaan yang berlanjut atas bahan baku ini dalam jangka panjang akan meningkatkan produktivitas pekerja dan sekaligus meningkatkan skala ekonomi industri kecil batik tulis Trusmi.

Penelitian lain juga dilakukan oleh Giyanto (2010) "Pengaruh Modal Usaha, Tenaga Kerja, Tingkat Pendidikan, Pengalaman Usaha, Jangkauan Pemasaran Dan Krisis Ekonomi Terhadap Keberhasilan Batik Di kampung Batik Kliwonan Kecamatan Masaran Kabupaten Sragen". Dengan model analisis data menggunakan regresi linier barganda menggunakan variabel dummy. Hasil analisis menujukan bahwa besarnya modal usaha berpengaruh terhadap keuntungan usaha batik, jumlah tenaga kerja berpengaruh terhadap keuntungan usaha batik, jangkauan pemesaran berpengaruh terhdapa keuntungan usaha batik, lamanya pengalaman usaha berpengaruh terhadap keuntungan usaha batik, dan krisis ekonomi juga berpengaruh terhadap keuntungan usaha batik di
Desa Kliwonan Kecamatan Masran Kabupaten Sragen.

\section{METODE PENELITIAN}

Penelitian ini dilakukan di Desa Trusmi Kecamatan Plered Kabupaten Cirebon.Pemilihan lokasi dilakukan secara sengaja (purposive) dengan pertimbangan bahwa Desa Trusmi merupakan sentra produksi batik di Kabupaten Cirebon. Penelitian ini bertujuan untuk mengetahui hambatan-hambatan serta karakteristik UKM Batik Tulis Trusmi . Selain itu juga untuk mengetahui pengaruh faktor-faktor produksi terhadap produktivitas UKM Batik Tulis Trusmi di Desa Trusmi Kabupaten Cirebon.

Objek dalam penelitian ini adalah UKM Batik Tulis Trusmi . Populasi dalam penelitian ini adalah UKM-UKM Batik Tulis Trusmi di Desa Trusmi Kecamatan Plered Kabupaten Cirebon. Sampel yang digunakan dalam penelitian ini adalah sebagian dari populasi UKM-UKM Batik Tulis Trusmi tersebut. Pengambilan sampel dalam penelitian ini yaitu dengan cara convenience sampling yang artinya penentuan sampel berdasarkan kebetulan dengan jumlah sempel sebanyak 30 perajin UKM Batik Tulis Trusmi .

Penelitian ini menggunakan analisis deskriptif dan model ekonometrika. Analisis deskriptif dilakukan dengan tujuan untuk mengetahui hambatan-hambatan dan karakterisrtik UKM Batik Tulis Trusmi di Desa Trusmi kabupaten Cirebon. Sementara model ekonometrika dalam penelitian ini mengacu pada penelitian sebelumnya yang dilakun oleh Sutopo (2011), untuk mengetahui produktivitas ia menggunakan formula fungsi produksi Zvi Griliches dan Jacues Mairesse. Sedangkan dari penelitian yang dilakukan oleh Mandala (2012) produktivitas diukur berdasarkan jumlah output yang dihasilkan dibagi dengan jumlah input yang digunkan. Pengukuran dilakukan dengan melihat input yang digunakan (dalam satuan rupiah) dan output yang didapatkan (dalam satuan rupiah). Dalam penelitian ini model ekonometrika bertujuan untuk mengetahui pengaruh faktor-faktor produksi terhadap produktivitas UKM. Oleh karena itu penelitian ini menggunakan data kuantitatif untuk mengetahui peran secara kuantitatif dari variabel bahan baku, tenaga kerja, pendidikan, upah dan pengalaman usaha yang berpengaruh terhadap produktivitas. Pengujian dilakukan dengan regresi linier berganda yang model ekonometrikanya ialah sebagai berikut:

$$
\mathrm{Y}=\beta 0+\beta 1 \mathrm{X} 1+\beta 2 \mathrm{X} 2+\beta 3 \mathrm{X} 3+\beta 4 \mathrm{X} 4+\beta 5 \mathrm{X} 5
$$

$+\beta 6 \mathrm{X} 6+\mathrm{e}$

\section{Keterangan:}

$\mathrm{Y}=$ Produksi adalah produksi batik yang dihasilkan pembatik, ukuran Rupiah 
$\mathrm{X} 1=\quad$ Bahan Baku adalah nilai nominal bahan baku yang digunakan untuk proses membatik dalam ukuran Rupiah

$\mathrm{X} 2=\quad$ Upah adalah biaya untuk tenaga kerja dengan ukuran Rupiah

X3 = Tenaga Kerja yang digunakan untuk produksi batik, ukuran Jiwa

X4 = Tingkat Pendidikan adalah tingkat pendidikan formal yang ditamatkan pemilik usaha batik dengan ukuran dumi

X5 $=$ Pengalaman Usaha adalah waktu berdirinya usaha sampai penelitian ini dijalankan, ukuran tahun

$\beta 1 \beta 6=$ Koefisien variabel

$\beta 0=$ Intersep

$\mathrm{e}=$ Error Term

Penelitian ini bersifat replikatif berdasarkan penelitian-penelitian sebelumnya.Beberapa contohcontoh penelitian sebelumnya dilakukan oleh Sutopo (2010), Mandala (2012), Arshad dan Natha (2013), dan Giyanto (2010).Namun yang membedakan penelitian ini dengan penelitian yang terdahulu adalah variabel-variabel yang digunakan dan pemilihan lokasi atau objek penelitian.

\section{HASIL PENELITIAN DAN PEMBAHASAN}

Analisis deskriptif menumjukan hasil pemilik UKM Batik Tulis Trusmi sebanyak 15 perajin merupakan usaha yang didirikan oleh sendiri dan sebanyak 15 perajin sisanya merupakan usaha yang diwariskan oleh orang tuanya atau usaha tersebut merupakan hasil dari turun tenurun.Rata-rara pendidikan pemilik usaha Batik Tulis Trusmiadalah lulusan SMA.Berdasarkan Analisis deskriptif menunjukan 23 perajin Batik Tulis Trusmi atau pemilik usaha merupakan lulusan SMA $(76.7 \%)$, dan sebanyak 7 perajin merupakan lulusan SMP (23.3\%).

Dari penelitian deskriptif menunjukan, produk atau output yang dihasilkan para perajin UKM Batik Tulis Trusmi, yaitu rata-rata berupa hem/kemeja, sarung, slendang dan sarimbit. Dalam pemasarannya para perajin memasok ke sujumlah showroom-showroom yang ada di Daerah Trusmi Kabupaten Cirebon dan dikirim ke daerah-daerah di di luar Cirebon seperti Jakarta, Banten, Bandung, daerah-daerah di Jawa tengah dan daearah-daerah di luar pulau jawa.

Para perajin UKM Batik Tulis Trusmi mengalami kesulitan dan hambatan dalam hal permodalan, bahan baku, dan SDM yang dimiliki. Disamping itu perajainBatik Tulis Trusmimengalami kesulitan dalam hal bahan baku berjumlah $20 \%$ perajin, dan yang mengalami kesulitan dalam sektor modal, bahan baku dan SDM sebesar $80 \%$.
Uji regresi liner berganda digunakan untuk menguji pengaruh variabel-variabel bahan baku (X1), upah (X2), tenaga kerja (X3), tingkat pendidikan (X4), dan pengalaman usaha (X5). Pada Tabel 1 menunjukan hasil analisis regresi linier berganda variabel-variabel independen terhadap variabel dependen.

Table 1

Hasil analisis regresi linier berganda

\begin{tabular}{|l|c|c|c|}
\hline $\begin{array}{c}\text { Variabe } \\
1 \\
\text { depende } \\
\mathrm{n}\end{array}$ & $\begin{array}{c}\text { Variable } \\
\text { Independ } \\
\text { en }\end{array}$ & Koefisien & t-hitung \\
\hline $\mathrm{Y}$ & $\mathrm{C}^{*}$ & -6321316 & -1.879141 \\
\hline & $\mathrm{X} 1 *$ & 1.104306 & 2.738832 \\
\hline & $\mathrm{X} 2 *$ & 2.672381 & 2.876585 \\
\hline & $\mathrm{X} 3$ & -490787.7 & -0.379561 \\
\hline & $\mathrm{X} 4$ & 101660.8 & 1.395911 \\
\hline & $\mathrm{X} 5$ & 322811.6 & 1.187025 \\
\hline $\begin{array}{l}\mathrm{F}- \\
\text { hitung }= \\
42.12\end{array}$ & $\begin{array}{c}\text { R-squared }=0.98 \\
\text { Adjusted R-squared }=0.97\end{array}$ \\
\hline
\end{tabular}

Keterangan: tanda * signifikan pada 0,05 dan tanpa tanda $*$ tidak signifikan

Sumber: Data Primer, diolah

Untuk mengetahuifaktor-faktor yang berpengaruh terhadap produksi Batik Tulis Trusmi dianalisis dengan regresi linier berganda dengan jumlah sampel 30 perajin UKM batik. Uji statistik pada model persamaan regresi linier berganda dalam penelitian ini adalah uji $\mathrm{T}$ yang merupakan pengujian secara individual (parsial), uji $\mathrm{F}$ yang menunjukan apakah semua variabel bebas yang dimasukkan dalam model berpengaruh secara bersama-sama terhadap variabel independen dan uji koefisien determinasi $\left(\mathrm{R}^{2}\right)$ untuk mengetahui seberapa besar variabel dependen (Y) dapat dijelaskan dengan variabel independen $(\mathrm{Xi})$.

Dengan berdasar Tabel 1 dapat dilihat bahwa Variabel Bahan Baku (X1) berpengaruh positif dan signifikan dengan tingkat signifikan sebesar 0,05terhadap jumlah produksi Batik Tulis Trusmi dengan koefisien regresi 1,104306, ini dapat dilihat dari nilai t-hitung $(2,738832)$ lebih besar dari t-tabel (1,711). Hasil ini menunjukan semakin besar jumlah bahan baku yang digunakan dalam produksi Batik Tulis Trusmi , semakin tinggi pula jumlah hasil produksi yang didapatkan. Sebaliknya semakin kecil bahan baku yang digunakan dalam produksi, maka semakin kecil pula jumlah hasil produksi yang diperoleh oleh pengusaha Batik Tulis Trusmi. Nilai koefisien $\beta 1$ sebesar 1,104306 menunjukan bahwa 
jika bahan baku yang digunakan dalam produksi meningkat 1 rupiah maka jumlah produksi yang dihasilkan pengusaha Batik Tulis Trusmi meningkat sebesar 1,104306 rupiah.

Dari Tabel 1 menunjukan bahwa Tingkat Upah (X2) berpengaruh positif dan signifikan terhadap jumlah produksi Batik Tulis Trusmi dengan koefisien regresi 2,672381. Hal ini karena nilai $t$ hitung $(2,738832)$ lebih besar dari t-tabel $(1,711)$, dengan tingkat signifikan 0,05 . Hasil ini menujukan bahwa tingkat upah yang diperoleh tenaga kerja akan berpengaruh terhadap jumlah produksi yang dihasilkan. Semakin besar tingkat upah pekerja, semakin tinggi pula jumlah produksi yang dihasilkan. Begitupun sebaliknya semakin rendah tingkat upah pekerja, semakin sedikit jumlah produksi Batik Tulis Trusmi yang dihasilkan. Nilai koefisien $\beta 2$ sebesar 2,672381 menunjukan bahwa tingkat upah meningkat 1 rupiah, maka jumlah produksi yang dihasilkan pengusaha Batik Tulis Trusmi meningkat sebesar 2,672381 rupiah.

Jumlah tenaga kerja (X3) tidak berpengaruh signifikan terhadap jumlah produksi Batik Tulis Trusmi, hal ini dikarenakan nilai t-hitung (0,379561) lebih kecil dari nilai t-tabel $(1,711)$, dengan tingkat signifikan sebesar 0,7076 lebih besar dari 0,05. Dalam hasil penelitian menunjukan bahwa jumlah tenaga kerja tidak berpengaruh signifikan terhadap jumlah produksi batik yang dihasilkan oleh UKM batik tulis trusmi.Pada dasarnya batik merupakan seni, sehingga pekerjaan membatik ini tidak semua orang bisa melakukannya.Tenaga kerja harus memiliki ketrampilan khusus dan nilai seni membatik, tenaga kerja yang tidak terampil tidak menambah produksi. Tambahan tenaga kerja tidak otomatis menambah jumlah produksi, karen sifat karakteristik batik itu memerlukan keahlian khusus, dalam hal ini para perajin batik untuk bisa membatik diperlukan pelatihan dan ketelitian sejak usia dini.

Pendidikan pekerja SMA keatas (X4) tidak berpengaruh dan tidak signifikan dengan koefisien regresi 101660.8. Hal ini dikarenakan nilai t-hitung $(1,395911)$ lebih kecil dari nilai t-tabel $(1,711)$, dengan tingkat signifikan besar dari 0,05. Sifat karakteristik batik memerlukan keahlian khusus dan nilai seni dan karsa yang khusus dalam hal ini para perajin batik untuk dapat membatik diperlukan pelatihan dan ketelitian sejak usia dini. Sehingga pendidikan formal para pekerja tidak berpengaruh terhadap produksi batik tulis trusmi.

Pengalaman usaha (X5) tidak berpengaruh signifikan dengan tingkat koefisien regresi sebesar 322811.6. Hal ini dikarenakan nilai t-hitung $(1,187025)$ lebih kecil dari nilait-tabel $(1,711)$, dengan tingkat signifikan sebesar 0,2468 lebih besar dari 0.05. Pengalaman yang diukur dari lamanya berusaha batik oleh pemilik usaha tidak mempengaruhi produksi batik. Pengusaha batik adalah produksi khusus yang berhubungan dengan pasar dan nilai jual, pengusaha yang tidak dibekali dengan ilmu pemasaran dan mengelolaan usaha yang turun temurun tidak akan meningkatkan nilai produksi karena tidak efisien dan produk yang dihasilkan kurang diserap pasar.

Variabel Bahan Baku (X1),Uupah (X2), Jumlah Tenaga Kerja (X3), Tingkat Pendidikan (X4) dan Pengalaman Usaha (X5) secara simultan (bersama-sama) perpengaruh terhadap jumlah produksi Batik Tulis Trusmi . Hal ini karena nilai Fhitung $(242,1259)>$ F-tabel $(2,76)$.

Koesisien determinasi yang diukur dengan adjusted R-square sebesar 0.976, ini menunjukan bahwa variabel-varibel Bahan Baku (X1), Upah (X2), Jumlah Tenaga Kerja (X3), Tingkat Pendidikan (X4) dan Pengalaman Usaha (X5) dapat menjelaskan Varian Jumlah Produksi Batik Tulis Trusmi sebesar $97,6 \%$, sedangkan 2,4\% lainnya dijelaskan oleh variabel yang tidak dimodelkan dalam penelitian ini.

\section{SIMPULAN}

Karakteristik pemilik/pengusaha batik tulis trusmi sebanyak $15(50 \%)$ perajin memulai usahanya berlatar belakang turun temurun/warisan dan sebanyak $15(50 \%)$ sisanya latar belakang usahanya berdiri sendiri.Tingkat pendidikn perajin didominasi SMA dan rata-rata usia perajin yaitu 51 tahun. Produk yang dihasilkan perajin berupa hem/kemeja, sarung, selendang dan sarimbit dalam pemasarannya perajin memasok kesejumlah showroom yang ada di trusmi dan dikirim kebeberapa daerah. Para perajin batik mengalami kesulitan dan hambatan dalam hal permodalan, bahan baku dan SDM. Regresi linier berganda dengan menggunakan uji individual tes (ujit) menunjukan bahwa bahan baku dan upah berpengaruh postif dan signifikan terhadap jumlah produksi batik, sementara jumlah tenaga kerja, pendidikan dan pengalaman usaha tidak berpengaruh. Secara bersama-sama dalam uji F varibel bahan baku, upah, jumlah tenaga kerja, pendidikan dan pengalaman usaha berpengaruh terhadap jumlah produksi batik tulis trusmi di Desa Trusmi Kecamatan Plered Kabupaten Cirebon.

\section{SARAN}

Menjaga ketersediaan bahan baku batik berupa kain mori, canting, malam atau lilin batik dan zat pewarna. Ketersediaan bahan baku tersebut sulit didapatkan dan harganya berfluktuasi. Menambah kemampuan dan ketangguhan pengusaha dalam proses produksi dan pemasaran hasil produksi, 
pemerintah daerah disarankan mengadakan pelatian menejemen produksi dan pemasaran batik. Tenaga kerja kebanyakan sudah berusia lanjut dan jarang dijumpai tenaga kerja muda yang menekuni uasaha membatik, disarankan untuk diadakan penyuluhan dan iklan untuk menarik kalangan muda untuk mencintai batik dan mau mempelajari proses membatik. Pendidikan khusus untuk meningkatkan ketrampilan dan minat membatik diperlukan agar Batik Tulis Trusmi tidak punah dan dapat diturunkan ke generasi selanjutnya.

\section{DAFTAR PUSTAKA}

Ariefianto, M. D. (2010). Ekonometrika Esensi dan Aplikasi Menggunakan Eviews. Jakarta, Indonesia: Erlangga.

Arsha, I. R., dan Ketut Suardikha Natha.(2013). "Pengaruh Tingkat Upah, Tenaga Kerja dan Modal Kerja Terhadap Produksi Industri Pakaian Jadi Tekstil (Studi Kasus di Kota Denpasar). E-Jurnal EP Unud (Agustus), hal. 393-400.

Arsyad, L. (1999). Ekonomi Mikro. Yogyakarta, Indonesia: BPFE-Yogyakarta.

Badan Pusat Statistik. (2014). PDB Atas Dasar Harga Konstan 2000 Menurut Lapangan Usaha. Jakarta. Indonesia.

Batik Tulis Trusmi Cirebon-Budaya Batik Yang Berdimensi Ragam Hias [Online]. Retrieved from http://batiktrusmi.co/batik-trusmicirebon-budaya-batik-yang-berdimensiragam-hias/ [4> Oktober 2014].

Boediono. (2011). Ekonomi Mikro: Pengantar Ilmu Ekonomi No. 1 (Sinopsis ed.). Yogyakarta, Indonesia: BPFE-Yogyakarta.

Dinas Perindustrian dan Perdagangan.(2014). Daftar Perajin Batik Kabupaten Cirebon 2013. Kabupaten Cirebon.

Disperindagkop dan UKM.(2014). Nilai produksi Batik Pekalongan.Kota Pekalongan.

Giyanto. (2010). Pengaruh Modal Usaha, Tenaga Kerja, Tingkat pendidikan, Pengalaman Usaha, Jangkauan Pemasaran dan Krisis Ekonomi Terhadap Keberhasilan Batik di Kampung Batik Kliwon Kecamatan Masaran Kabupaten Sragen. Tesis. Surakarta: Universitas Sebelas Maret.

Hakim, A. (2010).Analisis Efisiensi dan Produktivitas dengan Menggunakan Metode Data Envelopment Analysis dan Malmquist Productivity Index (Studi Kasus di PT Semen Gresik (PERSERO) Tbk).Skripsi. Yogyakarta: Universitas Islam Negeri Sunan Kalijaga.
Mandala, A. (2012). Peran Pendidikan, Pengalaman dan Inovasi Terhadap Produktivitas Usaha Kecil Menengah. Skripsi. Semarang: Universitas Diponegoro.

Mankiw, N. G. (2006). Principles Of Economics: Pengantar Ekonomi Mikro (3 ed.). (C. Sungkono, Trans.) Jakarta, Indonesia: Salemba Empat.

Masnedi. (2014). Akses Modal UKM: Batik Tulis Trusmi Cirebon Terhambat Modal [Online]. Retrieved from http://industri.bisnis.com/read/20120801/87/8 9178/akses-modal-ukm-batik-trusmi-cirebonterhambat-modal.[4 > Oktober 2014].

Muha. (2011). Sejarah Batik Tulis Trusmi [Online]. Retrieved from http://sanggarbatikkatura.com/classic/Sejarah \%20Batik\%20Trusmi.html.[ 4 . Oktober 2014].

Nicholson, W. Christopher Synder. (2010). Intermediate Microeconomics and Its Aplication (11 ed). USA: South-Western CHENGAGE Learning.

Putong, I. (2013). Economics: Pengantar Mikro dan Makro(Ed. 5). Jakarta, Indonesia: Mitra Wacana Media.

Samuelson, P. A., dan Nordhaus, W. D. (2003). Ilmu Mikro Ekonomi (17 ed.). (N. Rosyidah, E. Anna, \& C. Bosco, Trans.) Jakarta, Jakarta, Indonesia: PT. Media Global Edukasi.

Sarnowo, H., dan Danang Sunyoto. (2013). Pengantar Ilmu Ekonomi Mikro (Teori \& Soal) (Terbaru ed.). Yogyakarta, Indonesia: CAPS.

Soekesi, A. E. (2013). Upaya Peningkatan Kualitas Produk Batik Untuk Meningkatkan Daya Saing di Pasar Global Pada Sentra Batik Pasirsari Pekalongan. Prosidding Seminar Nasional Menuju Masyarakat Madani, hal. 2332.

Sudarsono.(1995). Pengantar Ekonomi Mikro. Jakarta, Indonesia: PT. Pustaka LP3ES.

Sudrajat, A. (2012). Indonesia Impor Batik Senilai Rp 285 Miliar [Online].Retrieved from http://www.kemenperin.go.id/artikel/5715/20 12,-Indonesia-Impor-Batik-Senilai-Rp-285Miliar.[4 > Oktober 2014].

Sukirno, Sadono. (2005). Mikro Ekonomi: Teori Pengantar (3 ed). Jakarta, Indonesia: PT Raja Grafindo Persada.

Sutopo, I. (2011). Produktivitas dan Ketahanan Bisnis Usaha Kecil Menengah (Studi Empiris Industri Batik Tulis Trusmi Kecamatan Plered Kabupaten Cirebon).Dinamika Keuangan dan Perbankan (Nopember), hal.102-112. 
Undang-undang Republik Indonesia No. 9 Tahun 1995: Tentang Usaha Kecil. Jakarta. Republik Indonesia.

Undang-undang Republik Indonesia No. 20: Tentang Usaha Mikro Kecil Menengah. Jakarta. Republik Indonesia.

Widarjono, A. (2013). Ekonometrika Pengantar dan Aplikasinya (4 ed.). Yogyakarta, Indonesia: UPP STIM YKPN. 